\title{
Investigation and comparison of the anti-tumor activities of lactoferrin, $\alpha$-lactalbumin, and $\beta$-lactoglobulin in A549, HT29, HepG2, and MDA231-LM2 tumor models
}

\author{
H. Y. Li, ${ }^{1,2,3 *}$ P. Li, ${ }^{1,2,3 *}$ H. G. Yang, ${ }^{1,2,3}$ Y. Z. Wang, ${ }^{1,2,3}$ G. X. Huang, ${ }^{1,2,3}$ J. Q. Wang, ${ }^{1,2,3}$ and N. Zheng ${ }^{1,2,3} \dagger$ \\ ${ }^{1}$ State Key Laboratory of Animal Nutrition, Institute of Animal Science, Chinese Academy of Agricultural Sciences, Beijing 100193, P. R. China \\ ${ }^{2}$ Key Laboratory of Quality \& Safety Control for Milk and Dairy Products of Ministry of Agriculture and Rural Affairs, Institute of Animal Science, \\ Chinese Academy of Agricultural Sciences, Beijing 100193, P. R. China \\ ${ }^{3}$ Laboratory of Quality and Safety Risk Assessment for Dairy Products of Ministry of Agriculture and Rural Affairs, Institute of Animal Sciences, \\ Chinese Academy of Agricultural Sciences, Beijing 100193, P. R. China
}

\section{ABSTRACT}

To investigate the anti-tumor activities of lactoferrin, $\alpha$-lactalbumin, and $\beta$-lactoglobulin, 4 types of human tumor cells (lung tumor cell A549, intestinal epithelial tumor cell HT29, hepatocellular cell HepG2, and breast cancer cell MDA231-LM2) were exposed to 3 proteins, respectively. The effects on cell proliferation, migration, and apoptosis were detected in vitro, and nude mice bearing tumors were administered the 3 proteins in vivo. Results showed that the 3 proteins $(20 \mathrm{~g} / \mathrm{L})$ inhibited viability and migration, as well as induced apoptosis, in 4 tumor cells to different degrees (compared with the control). In vivo, tumor weights in the HT29 group $(0.84 \pm 0.22 \mathrm{~g}$ vs. control $2.05 \pm 0.49 \mathrm{~g})$ and MDA231LM2 group $(1.11 \pm 0.25 \mathrm{~g}$ vs. control $2.49 \pm 0.57 \mathrm{~g})$ were significantly reduced by lactoferrin; tumor weights in the A549 group $(1.07 \pm 0.19 \mathrm{~g}$ vs. control $3.11 \pm$ $0.73 \mathrm{~g})$ and HepG2 group $(2.32 \pm 0.46 \mathrm{~g}$ vs. control 3.50 $\pm 0.74 \mathrm{~g})$ were significantly reduced by $\alpha$-lactalbumin. Moreover, the roles of lactoferrin, $\alpha$-lactalbumin, and $\beta$-lactoglobulin in regulating apoptotic proteins were validated. In summary, lactoferrin, $\alpha$-lactalbumin, and $\beta$-lactoglobulin were proven to inhibit growth and development of A549, HT29, HepG2, and MDA231-LM2 tumors to different degrees via induction of cell apoptosis.

Key words: lactoferrin, $\alpha$-lactalbumin, $\beta$-lactoglobulin, anti-tumor activity

\section{INTRODUCTION}

Cancer is expected to rank as the leading cause of death, as well as the single most important barrier to

Received February 4, 2019

Accepted March 23, 2019.

*These authors contributed equally to this work.

†Corresponding author: zhengnan_1980@126.com increasing life expectancy, in every country of the world in the 21st century. According to estimations from the World Health Organization in 2015, cancer is the first or second leading cause of death before the age of $70 \mathrm{yr}$ in 91 of 172 countries, and it ranks third or fourth in an additional 22 countries (Bray et al., 2018). Statistical data demonstrate that lung cancer is the leading cause of cancer death (18.4\% of the total cancer deaths), closely followed by colorectal cancer $(9.2 \%)$, liver cancer $(8.2 \%)$, and stomach cancer $(8.2 \%)$ for mortality (Bray et al., 2018). Cancer incidence and mortality are rapidly growing worldwide, making the prevention and therapy of cancer essential and pressing, and research and development of anti-tumor medicines are necessary.

Milk and dairy products are widely recommended as part of a healthy diet, and contain multiple functional proteins, UFA, trace elements, and so on (Chagas et al., 2012). In several studies, milk and dairy products were proven to play a key role in cancer prevention, especially in mouse adenocarcinomas and in a colorectal model (Tsuda et al., 2000), and inverse associations were observed between consumption of skim milk and cancers of the colon, rectum, breast, and ovary (Gallus et al., 2006). Meanwhile, regular milk intake could lower the risk of colorectal and bladder cancer, which might be related to the nutritional compositions of dairy products (Lampe, 2011). Therefore, the anti-tumor effect of the bioactive components and the particular mechanism require further evaluation and validation.

Considering milk and dairy products constitute an important part of the human diet, the biological effects of several nutritional components in milk and dairy products have attracted much attention in recent years, such as lactoferrin ( LF), $\alpha$-LA, and $\beta-L G$, which are synthesized in mammary epithelial cells and widely exist in dairy products. The 3-dimensional structures of the 3 proteins are shown in Figure 1. Lactoferrin $(80$ $\mathrm{kDa}$ ) is an iron-binding protein with approximately 700 AA residues, and widely exists in tears, milk, saliva, 


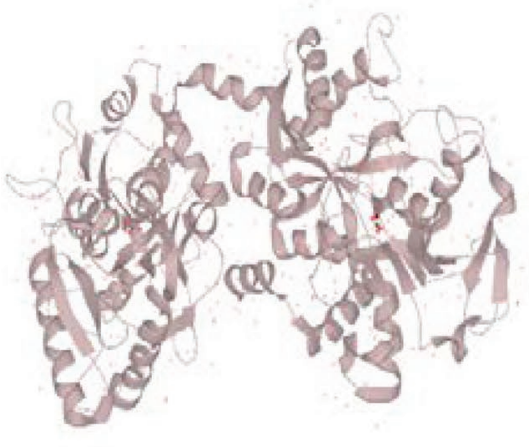

Lactoferrin

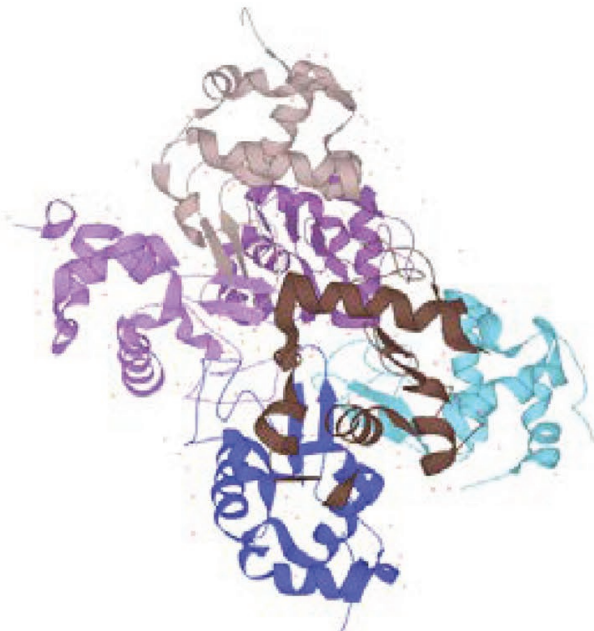

a-lactalbumin

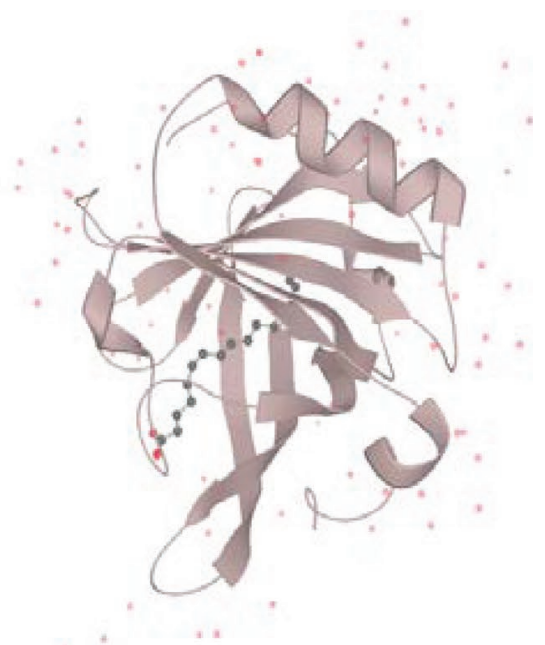

$\beta$-lactoglobulin

Figure 1. Structures of lactoferrin, $\alpha-L A$, and $\beta-L G$.

seminal fluid, bile, and synovial fluid secreted by mammals (Campbell, 1982; Małaczewska and Rotkiewicz, 2007). The concentration of LF in mammal milk depends on species, nutritional status, lactation time, and so on (Neville, 2000). Lactoferrin has several biological effects, including improvement of hypohemia (Chen et al., 2015, 2016), immunoregulation (Li et al., 2015), anti-inflammation (Bullen et al., 1972), anti-oxidation (Jia et al., 2006), anti-virus (Lu et al., 1985), and anti-tumor (Dominique, 2016; Donovan, 2016). In the anti-tumor mechanistic research of LF, it was proven to destroy the membrane of cancer cells, induce tumor cell apoptosis, block the tumor cell cycle, induce immune evasion, and so on (Tsuda et al., 2002). $\alpha$-Lactalbumin $(14.2 \mathrm{kDa})$ is synthesized in the rough endoplasmic reticulum of mammary epithelial cell, and promotes the synthesis of lactose (Permyakov and Berliner, 2000), suppresses inflammation through inhibiting cyclooxygenase-2 (Yamaguchi and Takai, 2014), alleviates damage in the gastrointestinal tract (Matsumoto et al., 2001), and so on. It is reported that $\alpha$-LA inhibited the growth of colon cancer, and the mechanism might be related to downregulating the levels of cyclooxygenase- 2 and prostaglandin $\mathrm{E}_{2}$, as well as binding with oleic acid or linoleic acid (Fang et al., 2012; Yamaguchi et al., 2014; Zhang et al., 2015). $\beta$-Lactoglobulin (18.4 $\mathrm{kDa}$ ) is a special whey carrier protein, synthesized and secreted in mammary epithelial cells, and provides basic ingredients for several bioactive peptides (Hattori et al., 1995; Jameson et al., 2002; Zimet and Livney, 2009; Liang and Subirade, 2010; Zhang, 2014; Wang et al., 2015a). $\beta$-Lactoglobulin is proven to have antiinflammatory, anti-virus, and anti-oxidation effects, lowering blood pressure and inhibiting tumors, mainly through combining with vitamins, lipids, and polyphenols (Nakamura et al., 1995; Mullally et al., 1997; Nagaoka et al., 2001; Sipola et al., 2002; Murakami et al., 2004; Zheng et al., 2018). In several studies, $\beta$-LG is validated to inhibit angiogenesis through interacting with $\mathrm{G}$ protein-coupled receptor kinase (Chougule et al., 2013); meanwhile, it exhibits important antiproliferative activity in the micromolar range through binding with riboflavin and forming $\beta-\mathrm{LG} /$ riboflavin nanocomplex (Diarrassouba et al., 2013).

However, the anti-tumor activities of LF, $\alpha$-LA, and $\beta$-LG have rarely been compared, and the sensitive cancer type of each bioactive protein has rarely been investigated in previous research. Therefore, in the present study, 4 tumor models were constructed in vitro and in vivo, aiming to evaluate the roles of the 3 proteins in inhibiting the viability and migration of tumor cells, in inducing cell apoptosis, as well as in suppressing the growth of solid tumors, which was also helpful to select and compare the sensitive cancer cell line of these proteins. To further investigate the underlying mechanism of the 3 bioactive proteins, the apoptosis proteins were also measured and investigated in 4 types of tumor cells, which demonstrated novelty when compared with the previous published studies.

\section{MATERIALS AND METHODS}

\section{Chemicals}

The A549, HT29, HepG2, and MDA231-LM2 cell lines were purchased from the Chinese Academy of 
Science (Shanghai, China), and Dulbecco's modified Eagle medium, F12 medium, RPMI-1640 medium, fetal bovine serum (FBS), and penicillin-streptomycin solution were purchased from Gibco (Grand Island, NY). Lactoferrin (iron-saturated), $\alpha-\mathrm{LA}$, and $\beta-\mathrm{LG}$ with purity all greater than $95 \%$, and methanol, crystal violet, and formaldehyde solution were purchased from Sigma-Aldrich (St. Louis, MO). The CCK-8 kit and Annexin-IV staining kit were purchased from Solarbio (Beijing, China). Antibodies of Bax, Bcl-2, caspase-3, and $\beta$-actin, as well as the related secondary antibodies, were purchased from Santa Cruz Biotechnology (Santa Cruz, CA). Reagents for the Western blotting assay were purchased from Solarbio. The enhanced chemiluminescence reagent was purchased from Thermo Fisher Scientific (Waltham, MA).

\section{Cell Culture}

The A549 cells were grown in F12 medium containing 10\% FBS. The HT29 cells and HepG2 cells were grown in RPMI-1640 medium and contained 10\% FBS. The MDA231-LM2 cells were grown in Dulbecco's modified Eagle medium and contained 10\% FBS. All of these cells were cultured, the growth medium was replaced with a fresh one every day, and the cells were propagated every $3 \mathrm{~d}$. All cells were cultured with $1 \%$ penicillin/ streptomycin in a humidified incubator (Thermo Fisher Scientific) at $37^{\circ} \mathrm{C}$ with $5 \% \mathrm{CO}_{2}$.

\section{Cell Proliferation Assay}

The 4 types of cells $\left(1 \times 10^{4}\right.$ cells in $120 \mu \mathrm{L}$ of growth medium per well) were plated into 96 -well plates and incubated for $36 \mathrm{~h}$, and the medium was replaced with $90 \mu \mathrm{L}$ of medium containing the indicated concentrations of LF, $\alpha-\mathrm{LA}$, or $\beta-\mathrm{LG}$, and cocultured for $48 \mathrm{~h}$. Then $10 \mu \mathrm{L}$ of CCK-8 solution (Engreen Biosystem, Beijing,China) was added into each well and cocultured for $4 \mathrm{~h}$, and the survival rates of cells were tested at the optical densities (A value) of $450 \mathrm{~nm}$ using a Microplate Reader (Thermo Fisher Scientific). The survival rate = $[($ A test - A blank $) /($ A control - A blank $)] \times 100 \%$.

\section{Transwell Migration Assay}

The migration capacities of 4 types of the cells were tested utilizing Transwell chambers (Corning Inc., Corning, NY). A total of $5 \times 10^{4}$ HT29 cells (per well) were put into the chamber with $150 \mu \mathrm{L}$ of serum-free medium. Three hundred microliters of medium containing $10 \%$ FBS was added into the outer chambers. Lactoferrin, $\alpha-\mathrm{LA}$, and $\beta$-LG samples (final concentration of $20 \mathrm{~g} / \mathrm{L}$ ) were individually added into the chambers and cocultured for $12 \mathrm{~h}$. The top surface of the filter was then scrubbed gently with clean cotton swabs, and the migrated cells on the undersurface were fixed with ice-cold methanol for $15 \mathrm{~min}$ and then stained with $0.15 \%$ crystal violet before washing with PBS buffer $(3 \mathrm{~min} \times 3)$. The stained cells were then photographed and counted. The mean number of stained cells was calculated in 3 random fields on each undersurface, and the numbers of migrated cells in the control group and in the bioactive protein-treated groups were analyzed and compared.

\section{Cell Apoptosis Analysis}

The 4 types of cells were plated into the 6 -well plate and treated with the 3 bioactive proteins (final concentration $20 \mathrm{~g} / \mathrm{L}$ ) for $48 \mathrm{~h}$. Then cells were collected and treated according to the instructions of the FITC-annexin $\mathrm{V}(\mathbf{A V})$ apoptosis detection kit (BD Biosciences, San Jose, CA). After being resuspended in $200 \mu \mathrm{L} 1 \times$ binding buffer, the cell suspension was incubated with $5 \mu \mathrm{L}$ of FITC-AV and $10 \mu \mathrm{L}$ of propidium iodide (PI; $10 \mathrm{~g} / \mathrm{L}$ ), and then gently vortexed and incubated for $10 \mathrm{~min}$ at room temperature in the dark. Then, 400 $\mu \mathrm{L}$ of $1 \times$ binding buffer was added into each tube and the cells were analyzed with flow cytometry within 2 h. Cells stained AV-/PI+ were considered as necrotic, $\mathrm{AV}+/ \mathrm{PI}+$ as late apoptotic, and AV+/PI- as early apoptotic.

\section{Western Blotting Analysis}

The 4 types of cells were plated in a 6 -well plate ( 1 $\times 10^{6}$ cells per well) with an intensity of $75 \%$, and 24 $\mathrm{h}$ later protein samples (final concentration $20 \mathrm{~g} / \mathrm{L}$ ) were added into the wells for $48 \mathrm{~h}$. Total proteins in the cells were lysed with lysis buffer (Solarbio) containing protease inhibitors, and then centrifuged at $10,000 \times$ $g$ at $4^{\circ} \mathrm{C}$ for $5 \mathrm{~min}$. Following heat treatment at $95^{\circ} \mathrm{C}$ with reducing loading buffer, the protein samples were added to 10\% SDS-polyacrylamide gels and the samples were transferred onto a nitrocellulose membrane by dry Trans-Blot machines (Bio-Rad, Hercules, CA) after electrophoresis assay. The membrane was blocked with 2.5\% BSA in Tris-buffered saline with Tween 20 for $1 \mathrm{~h}$ at $25^{\circ} \mathrm{C}$. The proteins including Bax, Bcl-2, caspase-3, and $\beta$-actin were then probed with primary antibodies for $2.5 \mathrm{~h}$ at $25^{\circ} \mathrm{C}$. $\beta$-Actin was used as the internal reference to correct equal loadings. After 3 washes with Tris-buffered saline with Tween $20(6 \mathrm{~min} \times 3)$, the membrane was incubated with secondary antibodies at $25^{\circ} \mathrm{C}$ for $1 \mathrm{~h}$ and then washed $(8 \min \times 3)$. The 
membrane was finally evaluated utilizing the enhanced chemiluminescence reagent kit and analyzed by Image J software (National Institutes of Health, Bethesda, MD).

\section{Animal Model}

To confirm the effect of the 3 bioactive proteins (LF, $\alpha$-LA, and $\beta$-LG) on A549, HT29, HepG2, and MDA231LM2 tumor inhibition, a nude mouse xenograft model was constructed. Eighty-eight male BALB/c nude mice (18-20 g) were chosen from Beijing Vital River Laboratory Animal Technology Co. Ltd. (Beijing, China), and 4 types of cells were cultured on a large scale. Then $5 \times 10^{7}$ cells in $200 \mu \mathrm{L}$ of Matrigel medium (Corning Inc.) were subcutaneously injected into the right flank of each nude mouse. When the tumor volume reached 90 to $100 \mathrm{~mm}^{3}$, the nude mice were randomly divided into 4 groups (6 or 5 mice per group): control (without treatment), LF group (100 mg/kg of BW, orally), $\alpha-\mathrm{LA}$ (100 mg/kg of BW, orally), and $\beta-\mathrm{LG}(100 \mathrm{mg} / \mathrm{kg}$ of $\mathrm{BW}$, orally). The mice were administered the bioactive proteins every $2 \mathrm{~d}$ at the same time. All mice were killed on d 25, and the tumors were weighed. All procedures for animal experimentation were performed according to Chinese guidelines for animal care, conforming to internationally accepted principles in the care and use of experimental animals (National Institutes of Health publication no. 80-23; US Department of Health and Human Services, 1978). Animal experiments were approved by the Ethics Committee of Chinese Academy of Agriculture Sciences (Beijing, China), with permission code CAS20181015. Individual tumor suppression rate $(\%)=($ the average tumor weight in the control

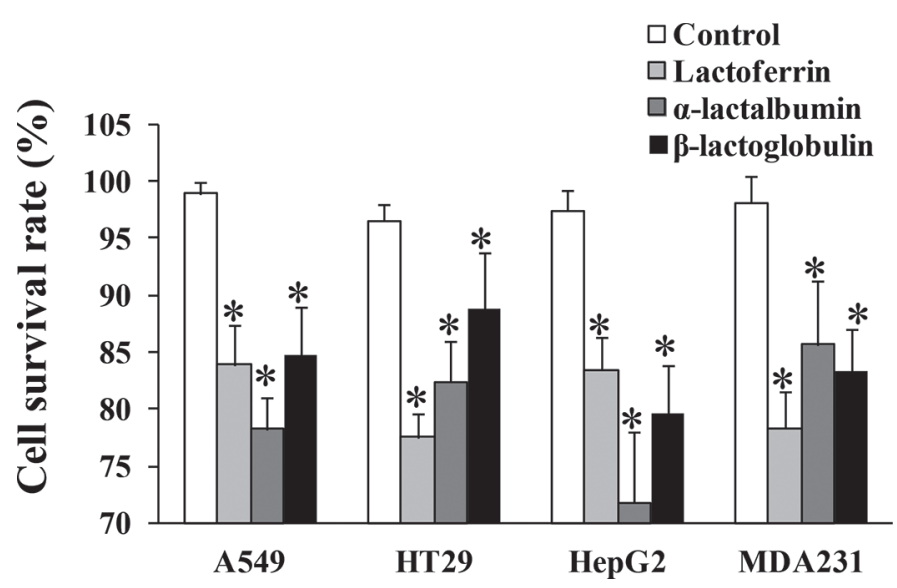

Figure 2. The viabilities of A549, HT29, HepG2, and MDA231LM2 cells affected by lactoferrin, $\alpha$-LA, and $\beta$-LG. Data expressed as mean \pm SD. ${ }^{*} P<0.05$ compared with control. group - the individual tumor weight in the proteins treatment groups)/the average tumor weight in the control group $\times 100 \%$. Relative tumor volume $($ RTV , $\%)=$ detected volume/volume before dosing $\times 100 \%$. Relative tumor proliferation rate $(\%)=\mathrm{RTV}$ of each tumor in the proteins treatment groups/the average RTV in the control group $\times 100 \%$.

\section{Statistical Analysis}

Data were expressed as mean \pm standard deviation. Statistical analyses were performed by ANOVA and Turkey's multiple comparison using the software SPSS 13.0 (SPSS Inc., Chicago, IL). A $P$-value less than 0.05 $(P<0.05)$ was considered statistically significant.

\section{RESULTS}

\section{$L F, \alpha-L A$, and $\beta-L G$ Inhibited the Viabilities of A549, HT29, HepG2, and MDA231-LM2 Cells to Different Degrees}

To confirm the effects of 3 bioactive proteins on the viabilities of 4 types of cells, cell survival rates were measured utilizing the CCK- 8 assay kit. The results demonstrated that in A549 cells, when compared with the control $(98.9 \pm 1.2 \%)$, under the same dosage $(20$ $\mathrm{g} / \mathrm{L}), \mathrm{LF}(83.9 \pm 3.5 \%, P<0.05), \alpha-\mathrm{LA}(78.2 \% \pm$ $2.9 \%, P<0.05)$, and $\beta$-LG $(84.8 \pm 4.1 \%, P<0.05)$ significantly inhibited cell viabilities; in HT29 cells, when compared with the control $(96.5 \pm 1.5 \%), \operatorname{LF}(77.5 \pm$ $2.1 \%, P<0.05), \alpha-\mathrm{LA}(82.4 \% \pm 3.5 \%, P<0.05)$, and $\beta$-LG $(88.8 \pm 4.9 \%, P<0.05)$ significantly inhibited cell viabilities; in HepG2 cells, when compared with the control $(97.4 \pm 1.9 \%), \mathrm{LF}(83.5 \% \pm 2.9 \%, P<$ $0.05), \alpha-\mathrm{LA}(71.8 \pm 6.2 \%, P<0.05)$, and $\beta$-LG $(79.6$ $\pm 4.3 \%, P<0.05)$ significantly inhibited cell viabilities; in MDA231-LM2 cells, when compared with the control $(98.1 \pm 2.3 \%), \mathrm{LF}(78.3 \% \pm 3.3 \%, P<0.05), \alpha-\mathrm{LA}$ $(85.7 \pm 5.5 \%, P<0.05)$, and $\beta-\mathrm{LG}(83.4 \pm 3.7 \%, P<$ $0.05)$ significantly inhibited cell viabilities (Figure 2 ).

Considering that the survival rates in $20 \mathrm{~g} / \mathrm{L}$ groups treated with the 3 bioactive proteins were above $90 \%$ in 4 types of cell models, $20 \mathrm{~g} / \mathrm{L}$ was regarded as the nontoxic and proper dosage of the 3 proteins, and was used in the subsequent experiments (Transwell and apoptosis assays).

$L F$, $\alpha-L A$, and $\beta-L G$ Inhibited the Migration of A549, HT29, HepG2, and MDA231-LM2 Cells to Different Degrees

The effects of LF, $\alpha-\mathrm{LA}$, and $\beta-\mathrm{LG}$ on the chemotactic motility of 4 types of tumor cells were detected 
by Transwell assays (Figure 3). As the statistical data in Figure 3B demonstrate, the 3 proteins with the dosage of $20 \mathrm{~g} / \mathrm{L}$ could significantly inhibit cell migration (compared with the control, $P<0.05$ ) to different degrees in 4 types of cell models.
$L F$, $\alpha-L A$, and $\beta-L G$ Induced the Apoptosis of A549, HT29, HepG2, and MDA231-LM2 Cells to Different Degrees

Utilizing Annexin-IV/PI staining, the effects of the 3 bioactive proteins in the apoptosis rate in 4 types of

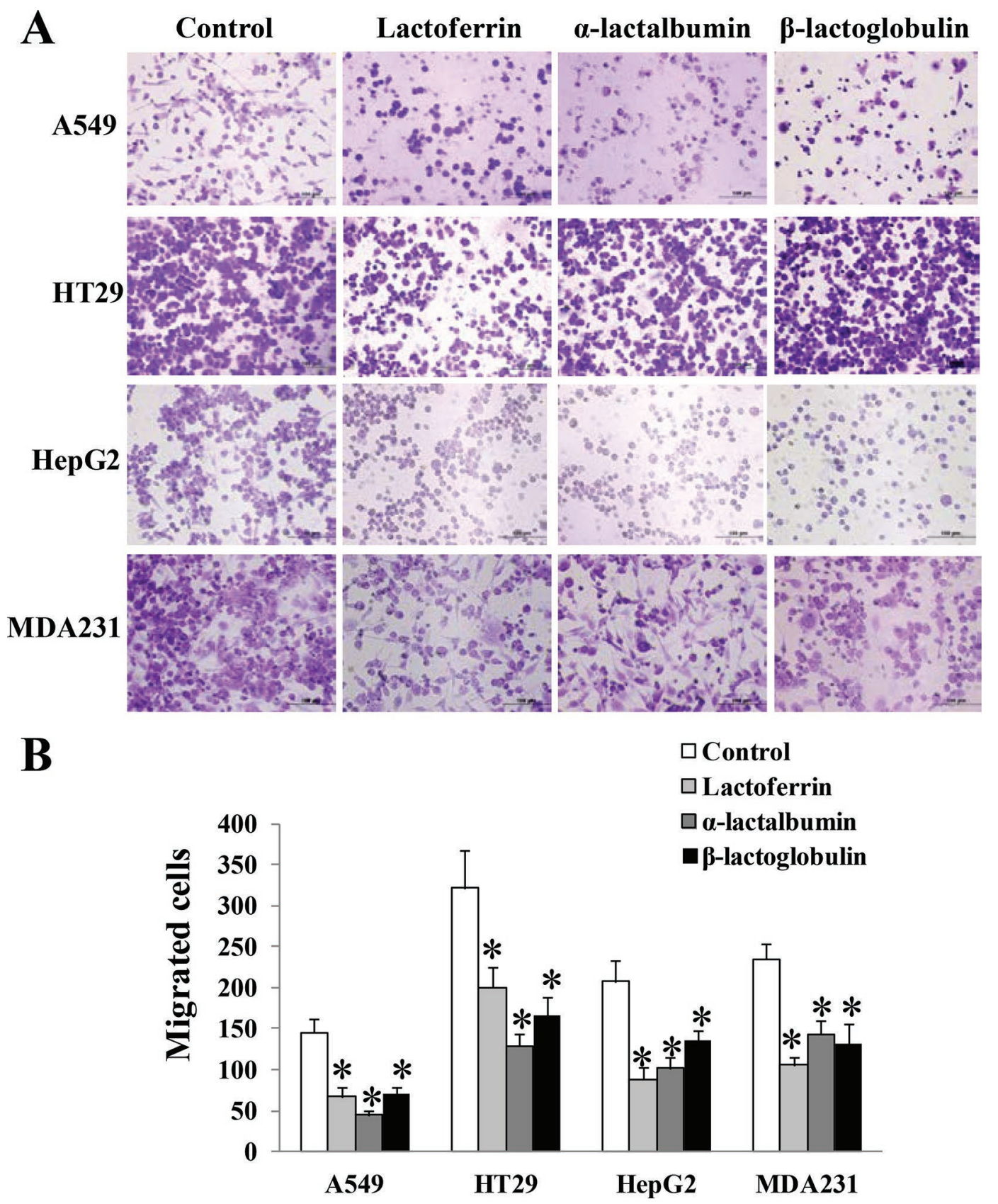

Figure 3. The effect of lactoferrin, $\alpha$-LA, and $\beta$-LG on the migration of A549, HT29, HepG2, and MDA231-LM2 cells. (A) Staining of the migrated tumor cells by Transwell assay (Corning Inc., Corning, NY). (B) Statistical analysis of the migrated cells. Data expressed as mean \pm SD. $* P<0.05$, compared with the control, $\mathrm{n}=3$. 
tumor cells were proven. Data in Figure 4 showed that LF, $\alpha$-LA, and $\beta$-LG upregulated apoptosis rates in 4 tumor cell models significantly (compared with the control, $P<0.05$ ), which suggested that the 3 bioactive proteins might have anti-tumor effects through inducing cell apoptosis.
$L F$, $\alpha-L A$, and $\beta-L G$ Showed Anti-Tumor Effects in A549/HT29/HepG2/MDA231-LM2

Tumor-Bearing Models

In the A549, HT29, HepG2, and MDA231-LM2 tumor model, when compared with the control, the 3

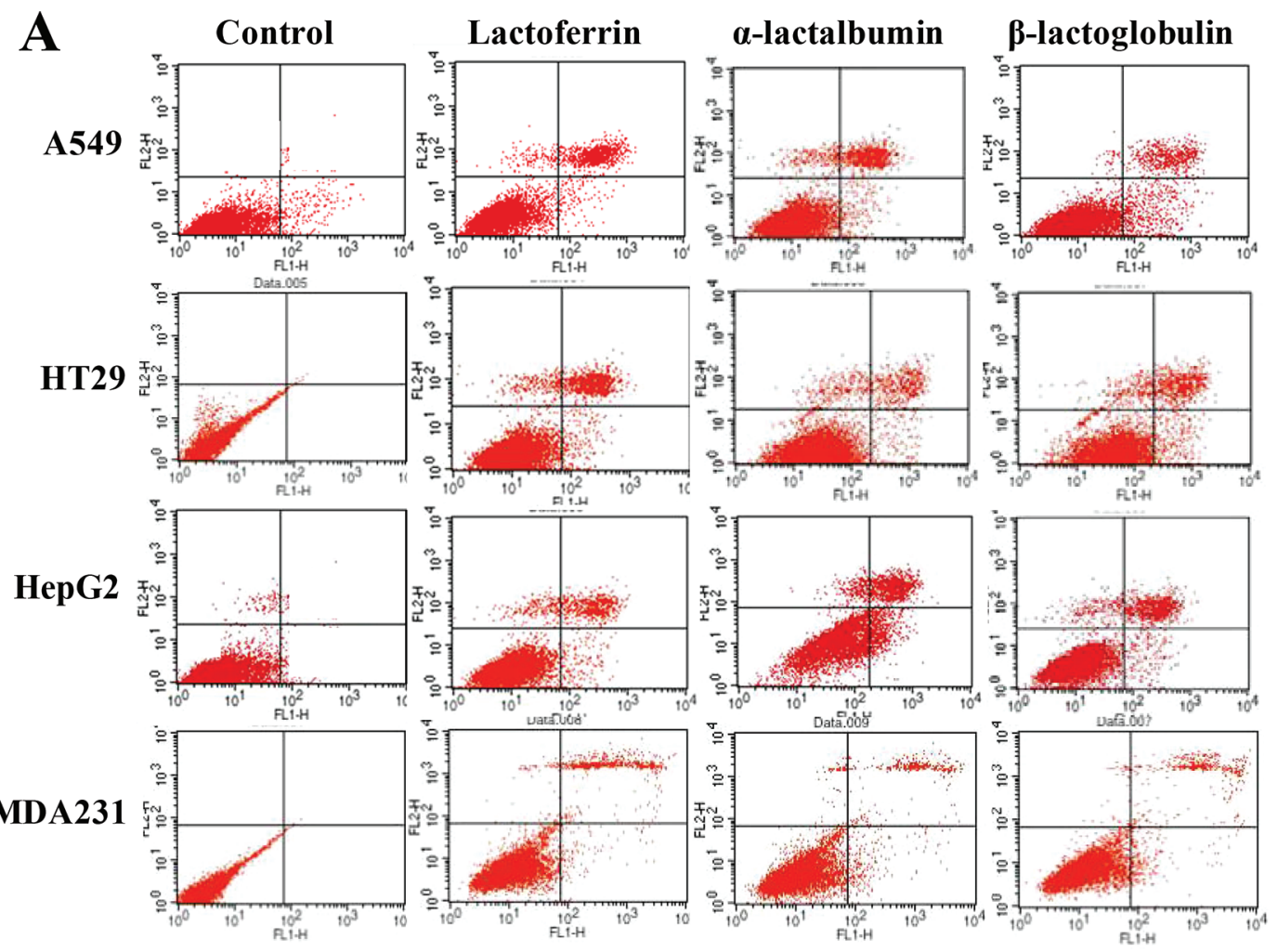

B

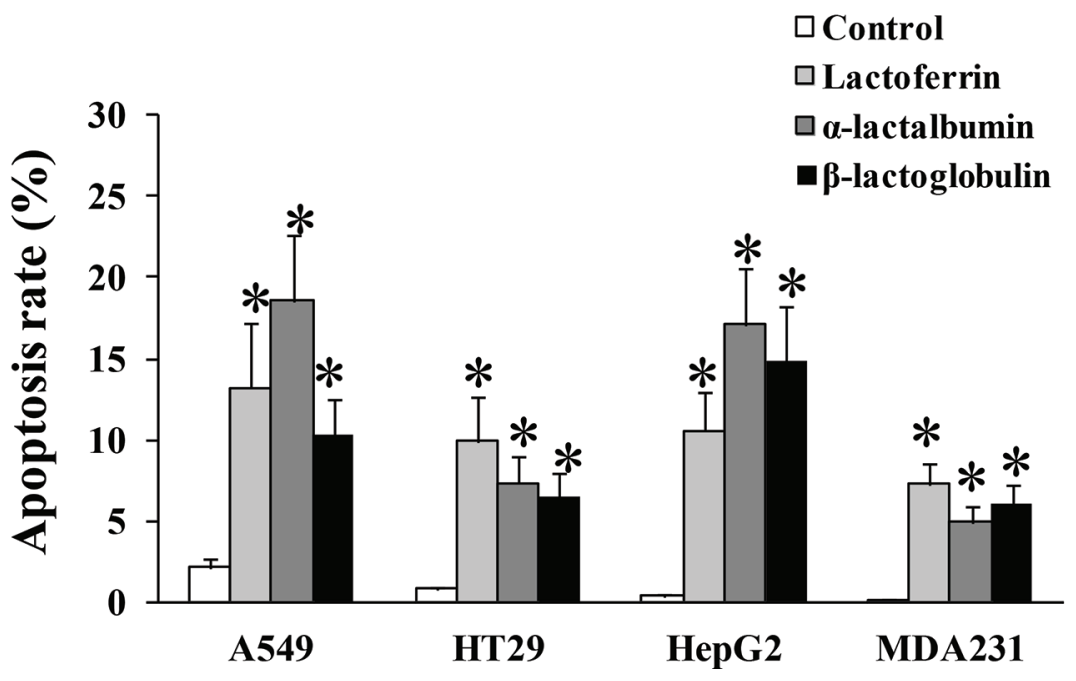

Figure 4. The effect of lactoferrin, $\alpha$-LA, and $\beta$-LG on the apoptosis of A549, HT29, HepG2, and MDA231-LM2 cells. (A) Demonstration of the apoptosis cells by fluorescence-activated cell sorting. (B) Statistical analysis of the apoptosis rate. Data expressed as mean \pm SD. ${ }^{*} P<$ 0.05 , compared with the control, $\mathrm{n}=3$. 
bioactive proteins inhibited tumor growth significantly (compared with the control, $P<0.05$ ) to different degrees (Figures 5 and 6), including increased tumor suppression rate and lower tumor relative proliferation rate (Table 1 ).

\section{LF, $\alpha-L A$, and $\beta-L G$ Activated Apoptosis Proteins in A549/HT29/HepG2/MDA231-LM2 Cells to Different Degrees}

In the present study, the effect of the 3 bioactive proteins on these related molecules was evaluated by Western blotting to elucidate the potential mechanism of 3 bioactive proteins on tumor growth and development. After treatment of the 3 bioactive proteins, Bax and Caspase-3 in 4 types of cells were upregulated significantly $(P<0.05)$, and the level of Bcl-2 in 4 types of cells decreased significantly $(P<0.05)$, when compared with the control (Figure 7).

\section{DISCUSSION}

Because of the high morbidity and mortality of cancer, research on clinical treatment and target drugs has become essential. Accumulated statistical data show that, in both sexes combined, lung cancer is the most commonly diagnosed cancer ( $11.6 \%$ of total cases) and the leading cause of cancer death $(18.4 \%$ of total cancer deaths), closely followed by breast cancer in females $(11.6 \%)$, prostate cancer $(7.1 \%)$, and colorectal cancer $(6.1 \%)$ for incidence, and colorectal cancer (9.2\%), stomach cancer $(8.2 \%)$, and liver cancer $(8.2 \%)$ for mortality. Because lung cancer, colorectal cancer, liver cancer, and breast cancer are the most frequent cancers and the leading causes of cancer death, we constructed A549, HT29, HepG2, and MDA231-LM2 cell models and tumor-bearing models to investigate the anti-tumor effects of LF, $\alpha-\mathrm{LA}$, and $\beta-\mathrm{LG}$, as well as evaluate the sensitive cancer cell line of each bioactive protein.

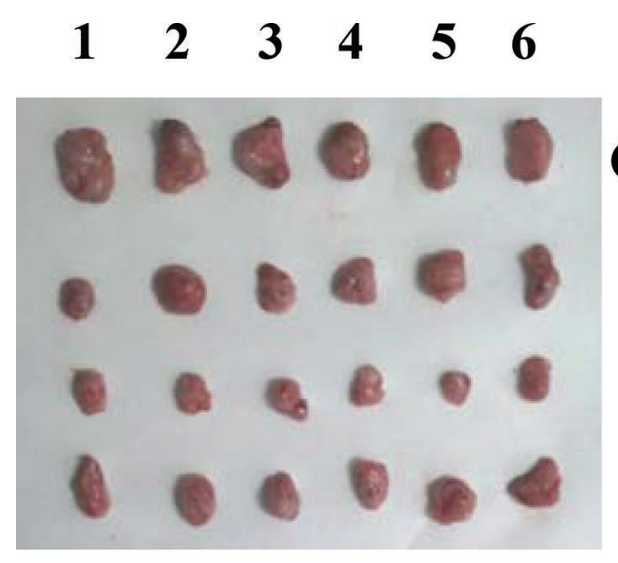

A549

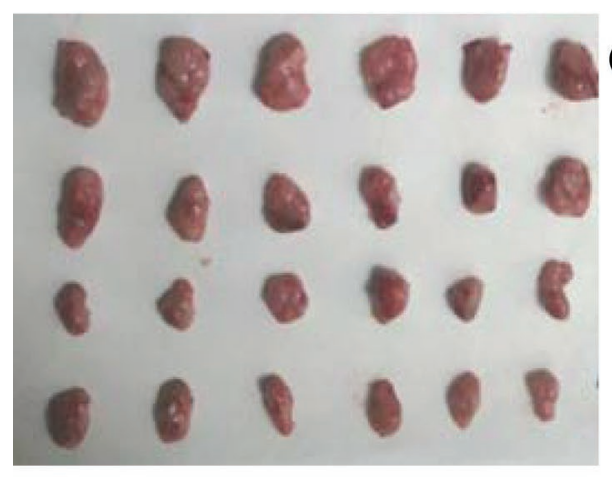

HepG2

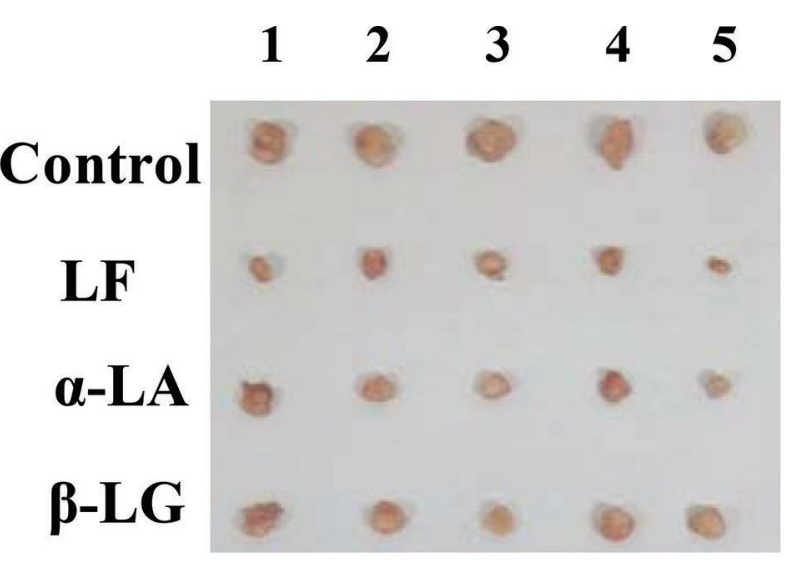

HT29

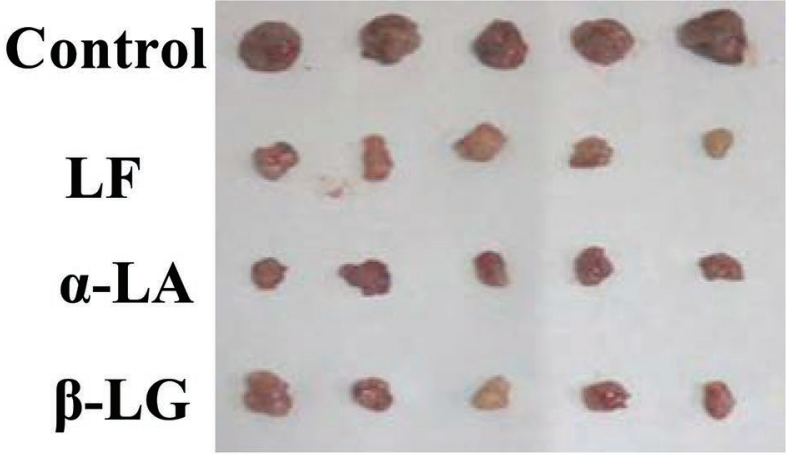

MDA231-LM2

Figure 5. Treatments of lactoferrin (LF), $\alpha$-LA, and $\beta$-LG decreased the sizes of A549, HT29, HepG2, and MDA231-LM2 tumors in the nude mice model. 
Based on the experimental results of cell viability, we found that LF was more sensitive in inhibiting the viabilities of HT29 cells and MDA231-LM2 cells, and

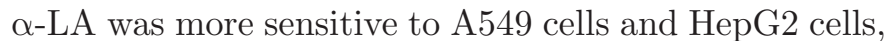
indicating that LF might be a potential anti-tumor medicine inhibiting the growth of colon cancer and breast cancer, and $\alpha-\mathrm{LA}$ might be medicative to the growth of lung cancer and liver cancer.

In the cell migration part, LF was proven to be more sensitive to HepG2 cells and MDA231-LM2 cells, $\alpha$-LA
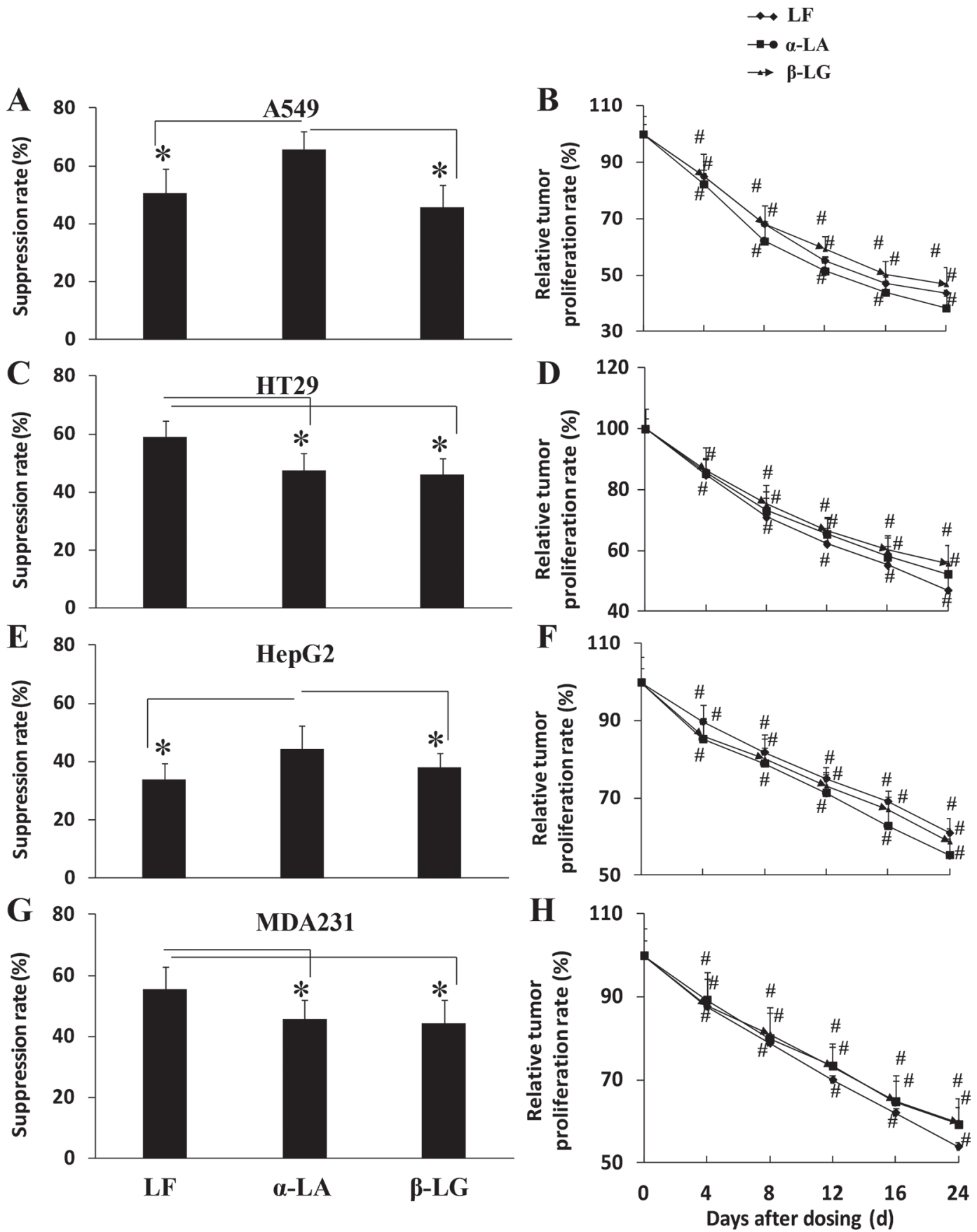

Figure 6. In vivo effects of lactoferrin (LF), $\alpha$-LA, and $\beta$-LG on A549, HT29, HepG2, MDA231-LM2 tumor-bearing nude mice. (A, C, E, and G) Tumor suppression rates in A549, HT29, HepG2, and MDA231-LM2 models, which were calculated by each tumor weight, respectively. ${ }^{*}<$ 0.05. $\mathrm{n}=6$ or 5. (B, D, F, and H) Relative tumor proliferation rates in A549, HT29, HepG2, and MDA231-LM2 models, which were calculated by relative tumor volumes of different groups. \#P<0.05, compared with the control (no treatment), $\mathrm{n}=6$ or 5 . Data expressed as mean \pm SD. 
Table 1. Tumor suppression rate (\%) in bioactive treatment groups ${ }^{1}$

\begin{tabular}{lccc}
\hline Group & LF & $\alpha$-LA & $\beta$-LG \\
\hline A549 & $50.48 \pm 8.49$ & $65.59 \pm 6.13^{*}$ & $45.66 \pm 7.75^{* *}$ \\
HT29 & $59.02 \pm 5.55$ & $47.32 \pm 6.36^{*}$ & $45.85 \pm 5.81^{*}$ \\
HepG2 & $33.71 \pm 5.80$ & $44.29 \pm 8.11^{*}$ & $38.04 \pm 4.39^{* *}$ \\
MDA231-LM2 & $55.42 \pm 7.54$ & $45.78 \pm 6.27^{*}$ & $44.18 \pm 7.28^{*}$ \\
\hline
\end{tabular}

${ }^{1}$ Tumor weight in each group is represented as mean $\pm \mathrm{SD}(\mathrm{n}=5$ or 6$)$ and analyzed by 1-way ANOVA. ${ }^{*} P<0.05$ vs. lactoferrin (LF) group; ${ }^{* *} P<0.01$ vs. $\alpha$-LA group.

was more sensitive to A549 cells and HT29 cells, indicating that LF might have effects in inhibiting the metastasis of liver and breast tumors, whereas $\alpha$-LA might be more effective to treat the metastasis of lung and colon tumors.

In the cell apoptosis part, LF was verified to be more sensitive to HT29 cells and MDA231-LM2 cells, Q-LA was found to be more sensitive to A549 cells and HepG2 cells; however, there seemed to be no significant difference of the apoptosis rate among the 3 bioactive protein treatment groups, further validating that all these proteins could inhibit tumor growth and development through induction of cell apoptosis.

In in vivo models, LF was proven to be more active in inhibiting the weights of HT29 tumors and MDA231 tumors, and $\alpha$-LA was more efficacious to suppress the tumor weight in the A549 model and HepG2 model, further verifying that LF and $\alpha$-LA were sensitive to different tumors, which was in accordance with the data in the cell viability session.

In the mechanism investigation session, several apoptotic proteins were detected by Western blotting, and the 3 bioactive proteins could induce apoptosis of 4 types of tumor cells to different degrees. One of the hallmarks of human cancers is the intrinsic or acquired resistance to apoptosis; evasion and failure of apoptosis might contribute to carcinogenesis, tumor progression, and also to treatment resistance because most current anticancer therapies, including chemotherapy, radiotherapy, and immunotherapy, primarily act by activating cell death pathways including apoptosis in cancer cells (Fulda, 2009). As the classical factors participating in cell apoptosis, Bax and Caspase-3 are well-known as enhancing factors, whereas Bcl-2 is an apoptosis inhibitor (Mitupatum et al., 2016; Wu et al., 2016; Liang et al., 2016). In several studies, LF was proven to inhibit the growth of colon cancer, liver cancer, lung cancer, and breast cancer through inducing tumor cell apoptosis. Li et al. (2017) reported that iron-saturated LF sample inhibited the growth and metastasis of HT29 tumor, mainly through inhibiting the VEGFR2-VEGFA-PI3K-Akt angiogenesis pathway. In the Morishita et al. (2015) hepatocarcinoma cell model, LF attenuated fatty acid-induced lipotoxicity via Akt signaling. In the lung cancer cell model, bovine LF (Lfcin-B) induced apoptosis of non-small cell lung cancer H460 cells through suppressing VEGF expression (Wang et al., 2015b). Wang et al. (2011) found that recombinant adenovirus containing human LF could inhibit EMT6 breast cancer through inducing tumor cell apoptosis in a mouse model. Referring to the antitumor mechanism of $\alpha$-LA, much research has found that $\alpha-\mathrm{LA}$, as well as the complex containing $\alpha-\mathrm{LA}$ and oleic acid, could inhibit tumor growth in vitro and in vivo through inducing tumor cell apoptosis (Svensson et al., 2000; Zhang et al., 2009; Fang et al., 2017). Additionally, $\beta-\mathrm{LG}$ was validated to inhibit the growth and metastasis of tumors in a lung cancer cell model, mainly through regulating an intrinsic mitochondrial pathway and inducing cell apoptosis. In the present study, the levels of Bax and Caspase- 3 were upregulated and the level of Bcl-2 decreased significantly, reflecting that milk and dairy products containing these bioactive proteins might suppress the growth and development of tumors through inducing cancer cell apoptosis.

Considering the multiple bioactivities of LF, $\alpha-\mathrm{LA}$, and $\beta-\mathrm{LG}$, their addition and application in food products (infant formula, fermentation milk, and so on) have been accepted and encouraged, whereas their potential as an anti-tumor therapeutic agent has not yet been evaluated and confirmed. The development of these proteins as clinical anticarcinogens, especially LF in colorectal tumors and female breast tumors, and $\alpha$-LA in lung tumors and liver tumors, requires further investigation and validation.

\section{CONCLUSIONS}

Lactoferrin, $\alpha$-LA, and $\beta$-LG were verified to exert a prominent anti-tumor effect in vitro and in vivo, which might occur via induction of the apoptosis of tumor cells. The potential anti-tumor activities of the 3 bioactive proteins deserve further attention.

\section{ACKNOWLEDGMENTS}

We are grateful for the support from 2 Key Laboratories, Key Laboratory of Quality \& Safety Control for 
A

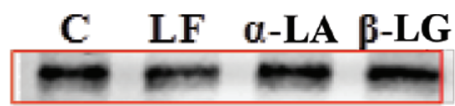

B-actin
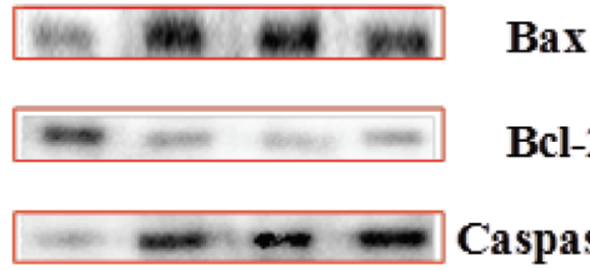

A549

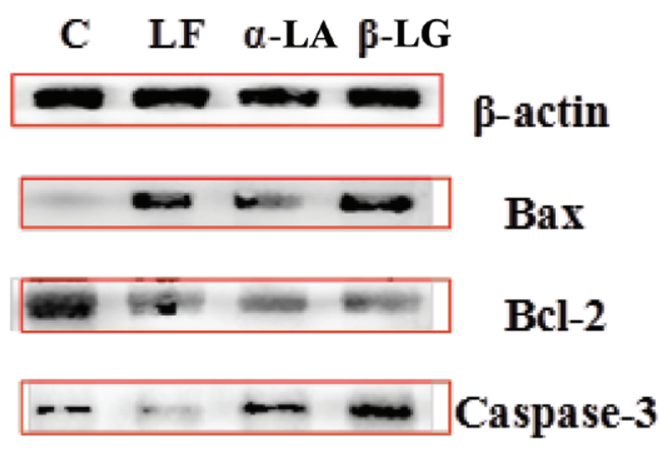

HepG2
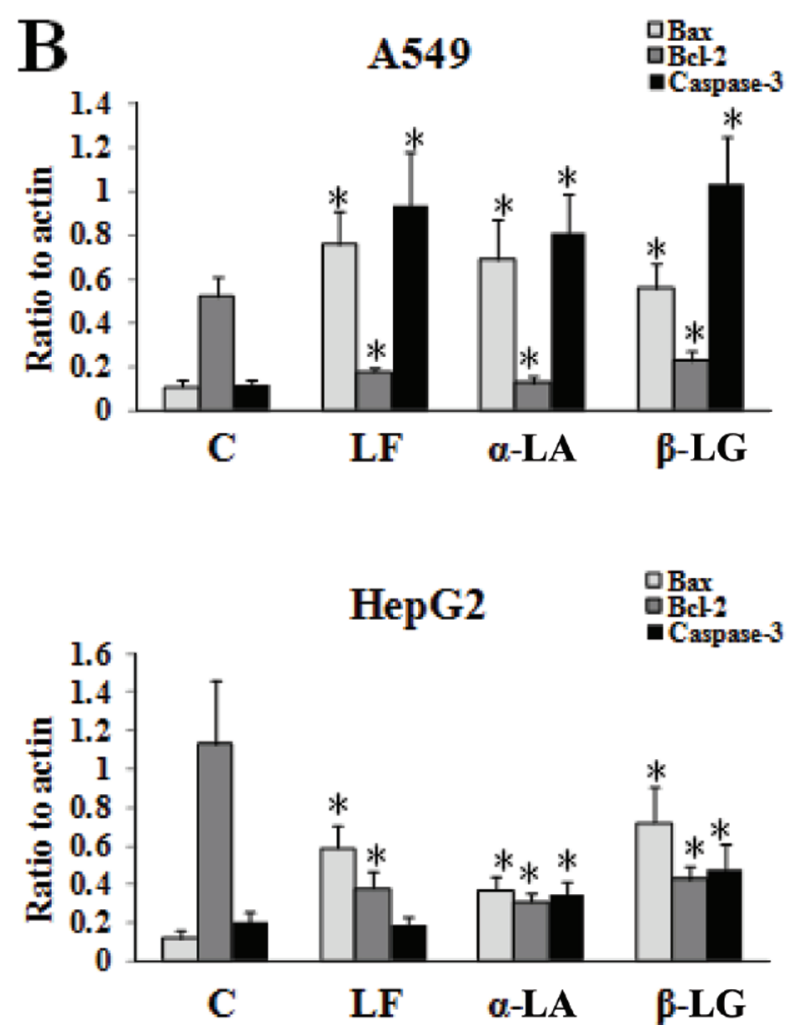

B
Bcl-2
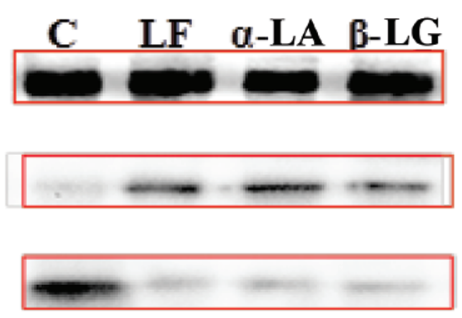

Caspase-3

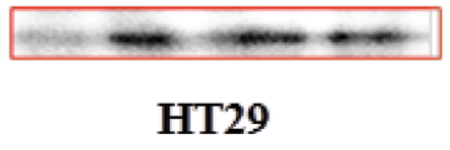

C LF $\alpha$-LA $\beta$-LG
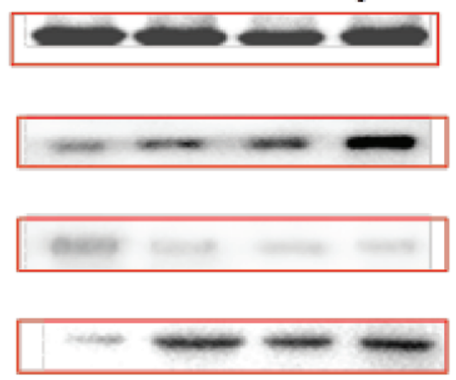

MDA231-LM2

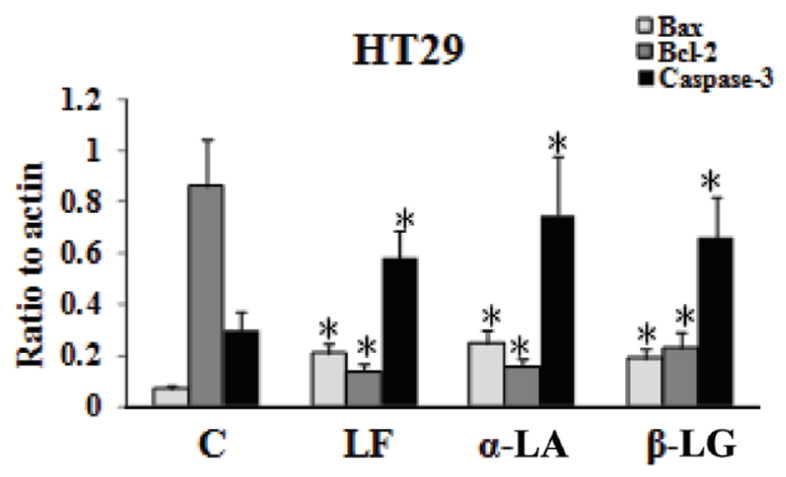

Figure 7. Expression of apoptotic proteins in A549, HT29, HepG2, and MDA231-LM2 cells treated with lactoferrin (LF), $\alpha$-LA, and $\beta$-LG.

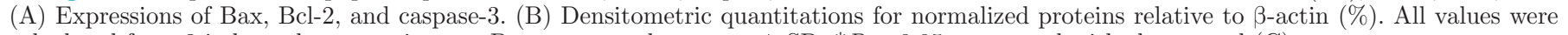
calculated from 3 independent experiments. Data expressed as mean $\pm \mathrm{SD} .{ }^{*} P<0.05$, compared with the control $(\mathrm{C})$. 
Milk and Dairy Products, Laboratory of Quality and Safety Risk Assessment for Dairy Products, Ministry of Agriculture and Rural Affairs, China. We thank support from Special Fund for Agro-Scientific Research in the Public Interest (201403071), the Ministry of Modern Agro-Industry Technology Research System of China (CARS-36), and the Agricultural Science and Technology Innovation Program (ASTIP-IAS12, Beijing, China).

\section{REFERENCES}

Bray, F., J. Ferlay, I. Soerjomataram, R. L. Siegel, L. A. Torre, and A. Jemal. 2018. Global cancer statistics 2018: GLOBOCAN estimates of incidence and mortality worldwide for 36 cancers in 185 countries. Cancer 68:394-424. https://doi.org/10.3322/caac.21492.

Bullen, J. J., H. J. Rogers, and L. Leigh. 1972. Iron-binding proteins in milk and resistance to Escherichia coli infection in infants. BMJ 1:69-75.

Campbell, E. J. 1982. Human leukocyte elastase, cathepsin G, and lactoferrin: Family of neutrophil granule glycoproteins that bind to an alveolar macrophage receptor. Proc. Natl. Acad. Sci. USA 79:6941-6945.

Chagas, C. E., M. M. Rogero, and L. A. Martini. 2012. Evaluating the links between intake of milk/dairy products and cancer. Nutr. Rev. 70:294-300.

Chen, K., L. Zhang, H. Li, Y. Zhang, H. M. Xu, J. Shao, W. Z. Tang, P. Yang, L. Y. Chen, and M. Meng. 2015. Iron metabolism in infants: Influence of bovine lactoferrin from iron-fortified formula. Nutrition 31:304-309.

Chen, L. Y., K. Chen, H. Li, Y. Zhang, H. M. Xu, J. Shao, and W. Z. Tang. 2016. A study on the effect of lactoferrin fortified formula milk on growth and blood erythrocyte indices among infants. Prev. Med. 28:682-686.

Chougule, R. A., S. P. Chougule, P. Bharathi, and A. H. S. Salimath 2013. Buffalo colostrum $\beta$-lactoglobulin inhibits VEGF-induced angiogenesis by interacting with $\mathrm{g}$ protein-coupled receptor kinase. Appl. Biochem. Biotechnol. 171:366-381.

Diarrassouba, F., L. Liang, G. Remondetto, and M. Subirade. 2013 Nanocomplex formation between riboflavin and $\beta$-lactoglobulin: Spectroscopic investigation and biological characterization. Food Res. Int. 52:557-567.

Dominique, L. 2016. Overview of lactoferrin as a natural immune modulator. J. Pediatr. 173:10-15.

Donovan, S. M. 2016. The role of lactoferrin in gastrointestinal and immune development and function: A preclinical perspective. J. Pediatr. 173:S16-S28.

Fang, B., M. Zhang, M. Jiang, H. Jing, and F. Z. Ren. 2012. Influence of $\mathrm{pH}$ on the structure and oleic acid binding ability of bovine $\alpha$-lactalbumin. Protein J. 31:564-572.

Fang, B., M. Zhang, H. Y. Wu, X. Fan, and F. Z. Ren. 2017. Internalization properties of the anti-tumor $\alpha$-lactalbumin-oleic acid complex. Int. J. Biol. Macromol. 96:44-51.

Fulda, S. 2009. Tumor resistance to apoptosis. Int. J. Cancer 124:511515.

Gallus, S., F. Bravi, R. Talamini, E. Negri, M. Montella, V. Ramazzotti, S. Franceschi, A. Giacosa, and C. L. Vecchia. 2006. Milk, dairy products and cancer risk (Italy). Cancer Causes Control $17: 429-437$.

Hattori, M., A. Watabe, and K. Takahashi. 1995. Beta-lactoglobulin protects beta-ionone related compounds from degradation by heating, oxidation, and irradiation. Biosci. Biotechnol. Biochem. 59:2295-2297.

Jameson, G. B., J. J. Adams, and L. K. Creamer. 2002. Flexibility, functionality and hydrophobicity of bovine $\beta$-lactoglobulin. Int. Dairy J. 12:319-329.
Jia, H. F., Z. F. He, H. He, L. N. Liu, and S. Y. Liu. 2006. Physiological functions of lactoferrin. Cereals and Oils 2:44-47.

Lampe, J. W. 2011. Dairy products and cancer. J. Am. Coll. Nutr. 30:464S-470S.

Li, H. Y., M. Li, C. C. Luo, J. Q. Wang, and N. Zheng. 2017. Lactoferrin exerts anti-tumor effects by inhibiting angiogenesis in a HT29 human colon tumor model. J. Agric. Food Chem. 65:10464-10472.

Li, W., K. Fu, X. Lv, Y. Wang, J. Wang, H. Li, W. Tian, and R. Cao. 2015. Lactoferrin suppresses lipopolysaccharide-induced endometritis in mice via down-regulation of the NF-kB pathway. Int. Immunopharmacol. 28:695-699.

Liang, L., and M. Subirade. 2010. Beta-lactoglobulin/folic acid complexes: Formation, characterization, and biological implication. J. Phys. Chem. B 114:6707-6712.

Liang, S., K. Sun, Y. Wang, S. Dong, C. Wang, L. Liu, and Y. Wu. 2016. Role of Cyt-C/caspases-9.3, Bax/Bcl-2 and the FAS death receptor pathway in apoptosis induced by zinc oxide nanoparticles in human aortic endothelial cells and the protective effect by alpha-lipoic acid. Chem. Biol. Interact. 258:40-51.

Lu, L., H. E. Broxmeyer, M. A. Moore, A. P. Sheridan, and P. Gentile. 1985. Abnormalities in myelopoietic regulatory interactions with acidic isoferritins and lactoferrin in mice infected with Friend virus complex: Association with altered expression of la antigens on effector and responding cells. Blood 65:91-99.

Małaczewska, J., and Z. Rotkiewicz. 2007. Lactoferrin - A multipotential protein. Med. Weter. 63:136-139.

Matsumoto, H., Y. Shimokawa, Y. Ushida, T. Toida, and H. Hayasawa. 2001. New biological function of bovine $\alpha$-lactalbumin: Protective effect against ethanol- and stress-induced gastric mucosal injury in rats. Biosci. Biotechnol. Biochem. 65:1104-1111.

Mitupatum, T., K. Aree, K. S. Kittisenachai, S. Roytrakul, S. Puthong, S. Kangsadalampai, and P. Rojpibulstit. 2016. mRNA Expression of Bax, Bcl-2, p53, Cathepsin B, Caspase-3 and Caspase-9 in the HepG2 cell line following induction by a novel monoclonal $\mathrm{Ab}$ Hep88 mAb: Cross-talk for paraptosis and apoptosis. Asian Pac. J. Cancer Prev. 17:703-712.

Morishita, S., K. Tomita, T. Ono, M. Murakoshi, K. Saito, K. Sugiyama, H. Nishino, and H. Kato. 2015. Lactoferrin attenuates fatty acid-induced lipotoxicity via Akt signaling in hepatocarcinoma cells. Biochem. Cell Biol. 93:566-573.

Mullally, M. M., H. Meisel, and R. J. Fitzgerald. 1997. Identification of a novel angiotensin-I-converting enzyme inhibitory peptide corresponding to a tryptic fragment of bovine $\beta$-lactoglobulin. FEBS Lett. 402:99-101

Murakami, M., H. Tonouchi, R. Takahashi, H. Kitazawa, Y. Kawai, H. Negishi, and T. Saito. 2004. Structural analysis of a new antihypertensive peptide ( $\beta$-lactosin B) isolated from a commercial whey product. J. Dairy Sci. 87:1967-1974.

Nagaoka, S., Y. Futamura, K. Miwa, T. Awano, K. Yamauchi, Y. Kanamaru, K. Tadashi, and T. Kuwata. 2001. Identification of novel hypocholesterolemic peptides derived from bovine milk B-lactoglobulin. Biochem. Biophys. Res. Commun. 281:11-17.

Nakamura, Y., N. Yamamoto, K. Sakai, and T. Takano. 1995. Antihypertensive effect of sour milk and peptides isolated from it that are inhibitors to angiotensin I-converting enzyme. J. Dairy Sci. $78: 1253-1257$

Neville, M. C. 2000. Lactoferrin secretion into milk: Comparison between bovine, murine and human milk. J. Anim. Sci. 78:26-35.

Permyakov, E. A., and L. J. Berliner. 2000. alpha-Lactalbumin: Structure and function. FEBS Lett. 473:269-274.

Sipola, M., P. Finckenberg, R. Korpela, H. Vapaatalo, and M. L. Nurminen. 2002. Effect of long-term intake of milk products on blood pressure in hypertensive rats. J. Dairy Res. 69:103-111.

Svensson, M., A. Hakansson, A. K. Mossberg, S. Linse, and C. Svanborg. 2000. Conversion of alpha-lactalbumin to a protein inducing apoptosis. Proc. Natl. Acad. Sci. USA 97:4221-4226.

Tsuda, H., K. Sekine, K. Fujita, and M. Ligo. 2002. Cancer prevention by bovine lactoferrin and underlying mechanisms: A review of experimental and clinical studies. Biochem. Cell Biol. 80:131-136. 
Tsuda, H., K. Sekine, Y. Ushida, T. Kuhara, N. Takasuka, M. Iigo, B. S. Han, and M. A. Moore. 2000. Milk and dairy products in cancer prevention: Focus on bovine lactoferrin. Mutat. Res. 462:227-233.

US Department of Health and Human Services. 1978. Guide for the Care and Use of Laboratory Animals. Rev. ed. Natl. Acad. Press, Washington, DC.

Wang, J., Q. W. Li, Y. T. Ou, Z. H. Han, K. Li, P. J. Wang, and S. B. Zhou. 2011. Inhibition of tumor growth by recombinant adenovirus containing human lactoferrin through inducing tumor cell apoptosis in mice bearing EMT6 breast cancer. Arch. Pharm. Res. 34:987-995.

Wang, L., H. Cheng, Y. Z. Ni, and L. Liang. 2015a. Encapsulation and protection of bioactive components based on ligand-binding property of $\beta$-lactoglobulin. J. Chin. Inst. Food. Sci. Tech. (Paris) 15:124-129.

Wang, S., J. C. Tu, C. J. Zhou, J. W. Li, L. Huang, L. Tao, and L. Zhao. 2015b. The effect of Lfcin-B on non-small cell lung cancer H460 cells is mediated by inhibiting VEGF expression and inducing apoptosis. Arch. Pharm. Res. 38:261-271.

Wu, R., S. Tang, M. Wang, X. Xu, C. Yao, and S. M. Wang. 2016. MicroRNA-497 induces apoptosis and suppresses proliferation via the Bcl-2/Bax-Caspase9-Caspase3 pathway and cyclin D2 protein in HUVECs. PLoS One 11:e0167052.

Yamaguchi, M., and S. Takai. 2014. Chronic administration of bovine milk-derived $\alpha$-lactalbumin improves glucose tolerance via enhancement of adiponectin in Goto-Kakizaki rats with type 2 diabetes. Biol. Pharm. Bull. 37:404-408.

Yamaguchi, M., S. Takai, A. Hosono, and T. Seki. 2014. Bovine milkderived $\alpha$-lactalbumin inhibits colon inflammation and carcinogenesis in azoxymethane and dextran sodium sulfate-treated mice. Biosci. Biotechnol. Biochem. 78:672-679.

Zhang, J. 2014. Protective effect of dairy protein to bioactive molecules vis their complexes. Jiangnan University 21-45.

Zhang, M., B. Fang, L. D. Zhang, and F. Z. Ren. 2015. Structure and anti-tumor activity of bovine $\alpha$-lactalbumin after binding linoleic acid. Guang Pu Xue Yu Guang Pu Fen Xi 35:2609-2612.

Zhang, M., F. Yang, J. Chen, C. Y. Zheng, and Y. Liang. 2009. Cytotoxic aggregates of alpha-lactalbumin induced by unsaturated fatty acid induce apoptosis in tumor cells. Chem. Biol. Interact. 180:131-142.

Zheng, G. Q., H. Y. Ji, S. J. Zhang, J. Yu, and A. J. Liu. 2018 Selenious- $\beta$-lactoglobulin induces the apoptosis of human lung cancer A549 cells via an intrinsic mitochondrial pathway. Cytotechnology 70:1551-1563.

Zimet, P. and Y. D. Livney. 2009. Beta-lactoglobulin and its nanocomplexes with pectin as vehicles for $\omega-3$ polyunsaturated fatty acids. Food Hydrocoll. 23:1120-1126. 